\title{
Script concordance testing to understand the hypothesis processes of undergraduate nursing students - Multiple case study
}

\author{
Marie-France Deschênes*1,2, Johanne Goudreau ${ }^{1,2}$ \\ ${ }^{1}$ Faculty of Nursing, Université de Montréal, Quebec, Canada \\ ${ }^{2}$ Center for innovation in nursing education (CIFI), Faculty of Nursing, Université de Montréal, Quebec, Canada
}

\author{
Received: December 14, 2020 \\ Accepted: February 4, 2021 \\ Online Published: March 15, 2021 \\ DOI: $10.5430 /$ jnep.v11n6p73 \\ URL: https://doi.org/10.5430/jnep.v11n6p73
}

\begin{abstract}
Background: Albeit essential to clinical reasoning (CR), strategies for generating student nursing clinical hypotheses at the time of transition to professional practice are underdeveloped. While script concordance testing (SCT) has been shown to be a valid and reliable assessment tool for $\mathrm{CR}$ in nursing education, the thought processes including the hypothesis processes involved in choosing an answer is not examined.

Methods: A multiple case study was used to understand the complex phenomenon of students' hypothesis activation and confrontation with the combined use of SCT questions and the think-aloud method. Structured individual interviews were conducted.

Results: A total of 18 students, nine first-year and nine third-year students participated in the study. The results show that the students demonstrate certain CR cognitive processes, including early representation of a clinical situation, semantic transformation of data, and hypothesis comparison.

Conclusions: Results suggest promoting knowledge articulation aloud and the frequent use of micro-judgments to compare and differentiate hypotheses involving the uncertainty of clinical practice, which underpin learning in successive layers.
\end{abstract}

Key Words: Clinical reasoning, Decision-making, Script concordance test, Uncertainty, Think aloud, Judgment, Education, Multiple case

\section{INTRODUCTION}

The development of clinical reasoning (CR) in undergraduate nursing education continues to be a challenge. ${ }^{[1]}$ While many teaching activities could promote the CR development, there remains a scarcity of valid tools to assess students' acquisition of this competency. ${ }^{[2,3]}$

Script concordance testing (SCT) has been shown to be a valid and reliable assessment tool for $\mathrm{CR}$ in nursing edu- cation, especially to reason in a context of uncertainty. ${ }^{[4,5]}$ In a SCT, students are asked to evaluate whether a new information minimized or reinforce a hypothesis related to a simulated clinical situation. However, the thought processes including the hypothesis processes involved in choosing an answer in a SCT is not examined. Answers can be chosen arbitrarily or based on misinterpretation of the SCT questions. ${ }^{[6-8]}$ Understanding how the nursing students cognitively cope with the SCT questions could help more deeply

\footnotetext{
* Correspondence: Marie-France Deschênes; Email: marie-france.deschenes@umontreal.ca; Address: Faculty of Nursing, Université de Montréal, Quebec, Canada.
} 
understand the phenomenon underlying the activation and the confrontation hypothesis comprised in nursing students' $\mathrm{CR}$ processes. It can also inform educators about teaching and learning strategies to facilitate $\mathrm{CR}$ development and assessment in nursing education. In the light of this, a multiple case study was used to understand the complex phenomenon of students' hypothesis activation and confrontation with the combined use of SCT questions and the think-aloud (TA) method.

\section{BACKGROUND}

\subsection{Clinical reasoning development}

$\mathrm{CR}$ is as a complex cognitive process of thinking and decision-making that is inseparably linked to clinical action. ${ }^{[9]} \mathrm{CR}$ in nursing encompasses "complex cognitive processes of using cognition, metacognition, and disciplinary knowledge to gather and analyze data, assess the meaning of the collected data for the purpose of making clinical intervention decisions" (Simmons, 2010, p. 1155). Goudreau

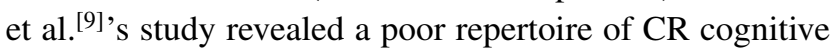
strategies in undergraduate nursing students, new nursing graduates, and nurses. The authors noted a predominance of applying interventions, i.e., "wanting to do something" rather than analyzing situational data and developing clinical hypotheses. Nurses barely analyzed, made few hypotheses, and as a result, their interventions were not always linked to the data collected and relied on routine procedure rather than CR process, ${ }^{[9]}$ thereby limiting the further development of $\mathrm{CR}$ expertise. In the study conducted by Goudreau et al., ${ }^{[9]}$ hypothesis processes strategies were only observed among a few graduate nursing students. This occurred too late, according to the authors, who also highlighted significant difficulties in further developing this competency after entry into practice. This scarcity regarding the use of cognitive strategies poses pedagogical challenges in terms of the educational strategies to be implemented to promote the optimal development of CR.

Crucial to $\mathrm{CR}$, hypothesis processes are essentially based on the use of knowledge networks, called scripts, which are organized and elaborated knowledge structures in long-term memory. ${ }^{[10,11]}$ Scripts begin to appear and develop when students are faced with their first clinical situations. Scripts are further developed and refined throughout their education program and nursing practice. Scripts enable the effective activation of knowledge for the rapid identification of key elements in a situation, leading to its understanding, the comparison of diverse clinical hypotheses, and the anticipation or prediction of the potential consequences of the situation. $^{[12-14]}$

\subsection{Script concordance testing}

Recent research or teaching activities in nursing education has investigated the pedagogical value of SCT, which is based on script theory. ${ }^{[4,8]}$ SCT is a cased-based exam involving the use of ambiguous and uncertain simulated situations in a vignette. A SCT typically includes around 20-30 vignettes that mirror clinical situations as authentically as possible. Each vignette is designed to represent how new information is processed during the $\mathrm{CR}$ in a context of uncertainty. After each vignette, there is a table with three columns: 1 -a plausible nursing hypothesis; 2-a new information; and 3-a micro-judgment to determine the significance of the new information in relation to the suggested hypothesis (see Figure 1). In a SCT, students' micro-judgments are compared to those acquired from a reference panel of experts, hence the notion of concordance.

Ms. Ouimet, 84, has had Alzheimer's disease for more than 10 years, making interaction with her
difficult. You begin a family meeting with Ms. Ouimet's two children: Marie and Fabrice. At the
beginning of the meeting, Marie reminds you that she lives at home with her mother and expresses how
disheartened and exhausted she feels in dealing with her mother's situation.

Figure 1. Nursing SCT vignette components 


\subsection{Background of the multiple case study}

Students involved in the multiple case study had previously completed a digital educational strategy based on script concordance in an asynchronous mode. ${ }^{[15]}$ Aiming at encouraging the activation and use of scripts, the educational strategy includes a digitalized SCT with incorporated expert feedback. Prior to the educational strategy's use with students, twelve nursing experts answer individually the SCT questions and provide comments to explain their choices. ${ }^{[16]}$ These comments were added to the SCT as feedback. The digital educational strategy included 81 questions relating to 22 vignettes in the context of general medical and surgical nursing care. Cronbach's alpha $(\alpha)$ coefficient ranged from 0.87 to $0.90 .^{[16]}$ When using the digital educational strategy, the student benefits from automated feedback that presents the experts' various CR processes. The first feedback presents the nursing experts' micro-judgment, while the second feedback presents the comments explaining their micro-judgment. A third type of feedback is intended to point out a key message for one or a set of vignettes and to provide the student with resources to consult.

As cognitive apprentices, students build knowledge in an active and autonomous manner in exercising several microjudgments while using the digital educational strategy. They rely on prior knowledge which is compared to the nursing experts' micro-judgment and explanations. ${ }^{[15]}$ The expert choices and interpretations in the educational strategy were reported highly diversified but also very instructive. Findings show the students' appreciation of the possibility to position themselves in relation to a professional group's judgment in solving real-life professional situations. ${ }^{[15,16]}$ However, it is unclear how the digital educational strategy based on script concordance actively engages the student to autonomously activate and confront hypotheses when answering SCT questions. To this end, we tried to understand the complex phenomenon of students' hypothesis activation and confrontation, in a synchronous mode, with the combined use of SCT questions and the TA method.

\section{CONCEPTUal Framework}

Prior to the study and to represent the activity of organizing knowledge (i.e., repertoire of nursing scripts), we developed a conceptual framework that incorporated script theory and cognitive companionship to accelerate the hypothesis processes in nursing students.

\subsection{Script theory}

Scripts are the "fuel" of CR. ${ }^{[17]}$ Hypotheses rapidly arise by the activation of scripts in an expert or a student who reasons in an efficient manner when faced with a clinical

Published by Sciedu Press situation. Scripts contain associative links between data. The activation of the scripts quickly gives access to the attributes (semantic qualifiers) of the data identified in the clinical situation, ${ }^{[12,13,17]}$ i.e., characteristics that appear significant. Semantic qualifiers are descriptors that can be used to compare and contrast key elements in a given situation. ${ }^{[18]}$ The translation of data from a clinical situation into professional practice terms requires a semantic transformation of the data, i.e., a cognitive data processing operation. ${ }^{[1-19]}$ In short, semantic transformation implies the transformation of the situation or patient-specific details into scientific terms of the discipline. For example, the presentation of a "new and intense pain" is translated as "acute pain", "He had this headache before" becomes a "recurrent headache". This ease in naming characteristics of a situation makes it easier to retrace salient information in long-term memory. ${ }^{[17-19]}$ This makes it possible to verify whether the current situation bears the same signature as that of its usual representation, schematized by the scripts. This search for alignment between the current situation and the scripts involves an active processing of the data to develop one or more hypotheses in order to consider the one that is the most probable in the circumstances. ${ }^{[12,13,17]}$

\subsection{Cognitive companionship}

Cognitive companionship aims to create an optimal social, dialogical and pedagogical interaction between students and experts, where the latter use educational strategies to foster students' practice of reflection (Collins, 1991; Collins et al., 1989) and thus, the acquisition of essential cognitive and metacognitive skills for the development of CR. ${ }^{[20,21]}$ The principles of cognitive companionship stipulate that offering a cognitive support adapted to students' level, as well as explicit teaching moments combining questioning, supervision, and constructive feedback, are essential in the development of complex competencies (Collins, 1991; Collins et al., 1989). It also involved student's articulation of knowledge and reflection on action. Articulation includes methods of getting students to articulate their knowledge or reasoning in a domain. One way to operationalize this principle is to use the TA method that makes more observable the processing of data from students' CR. ${ }^{[22]}$ It is considered as a cognitive process that enables the semantic transformation of data. ${ }^{[23]}$ Specifically, it allows elucidation of the reasoning processes undertaken. ${ }^{[24,25]}$ Finally, reflection on action allows students to compare their own clinical reasoning processes with those of experts, highlighting similarities and differences, and ultimately foster the competency development (Collins, 1991; Collins et al., 1989). 


\section{Method}

\subsection{Research design}

This study used a multiple case study approach ${ }^{[26]}$ as eighteen individual cases were examined to understand the complex phenomenon of students' hypothesis activation and confrontation with the combined use of SCT questions and the TA method. The multiple case study is a descriptive qualitative research design. ${ }^{[27-30]}$ Qualitative research design helped to examine broadly a complex phenomenon in its natural setting ${ }^{[30,31]}$ i.e., the hypothesis processes which underpins individual nursing undergraduate students' responses to SCT questions. It was thought that having test-takers verbalize their rationale while responding to SCT questions could provide a broader assessment of $\mathrm{CR}$ that is otherwise lost in the current format of SCT questions.

\subsection{Aim and question research}

The purpose of the multiple case study was to carry out an in-depth analysis ${ }^{[30]}$ of CR learning in more than one case (more than one student thought processes) at the undergraduate nursing education level. Students were asked to explain aloud their thought process that led to the choice of answer (micro-judgment) for each question of the SCT. This study was designed to answer the following question: Does the combined use of SCT and TA impact the learning of hypothesis processes by undergraduate nursing students? TA was used both as an educational intervention ${ }^{[22]}$ in conjunction with the SCT questions and as a data collection tool. Stemming from cognitive psychology, TA has been used as a research method since the 1980s. ${ }^{[32]}$ It is a method of collecting verbal data from a subject while he or she is performing a complex cognitive process. ${ }^{[23,24]}$

\subsection{Context and participants}

The study was carried out at a Canadian university Faculty of nursing. The university offers, among others, an undergraduate nursing program that gives the ability to apply to nursing practice to more than 200 students per year. This program implemented a competency-based approach. The duration of the program is three years, spread over six terms, and it requires 103 credits where each credit equals 45 hours of educational activity. First- and third-year students were invited to participate voluntarily in the study via an announcement on the university's student learning portal. Students at the beginning of their education program and those at the end of it were solicited in order to better distinguish the students' hypothesis processes at two different levels of training.

\subsection{Instrument}

An individual interviewing guide including SCT questions was used in order to understand the complex phenomenon of undergraduate nursing students' hypothesis activation and confrontation. Questions related to five SCT vignettes in nursing were combined with the TA method ${ }^{[23]}$ to examine the activation and confrontation of hypotheses by undergraduate nursing students. Five vignettes were used for each participant during one interview, as suggested in previous studies. ${ }^{[9,33]}$ The chosen vignettes were aligned to the participants 'current clinical stage and were validated in a previous study by two experts in nursing education. ${ }^{[16]}$ The students were presented with the same type of vignettes they got used to with the digital educational strategy, on a computer screen. At the same time, the primary researcher was reading aloud the vignettes, including the clinical situations and questions leading to micro-judgments. Students had to state aloud their micro-judgments and the rationale behind their micro-judgment for each of the questions in the vignette. Students were asked to verbalize their initial thoughts (What is happening in this situation? What are your thoughts at this moment?), how specific new information influenced the hypothesis proposed (If you were thinking to ... and then ...) and how they judged all the data of the situation (Taking into account all the facts of the situation, what are your thoughts? What is your impression?). Figure 2 presents the questions that were read to the students in the five vignettes used for data collection.

\subsection{Data collection}

Structured individuals' face-to-face interviews lasting 30 to 60 minutes were conducted between November 30, 2018 and December 21, 2018 to answer the following research question: Does the combined use of SCT and TA impact the learning of hypothesis processes by undergraduate nursing students? A digital audio recording device was used to record the interviews to ensure the data reported being accurate. ${ }^{[29]}$ All interviews were conducted by the principal researcher who was nor had been previously involved with the participants. Participants also completed a socio-demographic questionnaire that documented age, gender, current year of training, years of experience in the health and social services field, and previous academic studies. These data aimed to validate how previous clinical experience and other academic studies influence students' cognitive processes.

\subsection{Data analysis}

A deductive qualitative data analysis procedure followed that was guided by predetermined indicators, i.e., qualitative observations that make it possible to operationalize the development of the competence. ${ }^{[34]}$ Inference in the explanation of knowledge objects consists of comparing prior knowledge, in this case script theory, ${ }^{[12,35]}$ with the research data. Table 1 presents the indicators of effective $\mathrm{CR}$ as documented by 
Faucher et al. ${ }^{[17]}$ According to these authors, the develop- sure and the resolution of multiple situations in professional ment of CR goes hand in hand with the development and practice, these criteria correspond to cognitive operations organization of knowledge and leads to the script's construc- related to CR and inform about the level of development of tion in long-term memory. Closely related to clinical expo- CR. ${ }^{[17]}$

Ms. Ouimet, 84, has had Alzheimer's disease for more than 10 years, making interaction with her difficult. You begin a family meeting with Ms. Ouimet's two children: Marie and Fabrice. At the beginning of the meeting, Marie reminds you that she lives at home with her mother, and expresses how disheartened and exhausted she feels in dealing with her mother's situation.

\begin{tabular}{|c|c|c|}
\hline $\begin{array}{l}\text { Question } 2 \text { - If you are } \\
\text { thinking to ... }\end{array}$ & And then ... & \\
\hline $\begin{array}{l}\ldots \text { discuss with Marie and } \\
\text { Fabrice respite service } \\
\text { resources available in the } \\
\text { community for caregivers. }\end{array}$ & $\begin{array}{l}\text {... Marie mentions: "It's my } \\
\text { mother. I promised I'd take } \\
\text { care of her. I'll manage on my } \\
\text { own." }\end{array}$ & $\begin{array}{l}\text { How does this information } \\
\text { influence the hypothesis? }\end{array}$ \\
\hline $\begin{array}{l}\text { Question } 3 \text { - If you are } \\
\text { thinking to... }\end{array}$ & And then ... & \\
\hline $\begin{array}{l}\text {... explore with Marie and } \\
\text { Fabrice what would be the } \\
\text { best way to help them now. }\end{array}$ & $\begin{array}{l}\ldots \text { in contradiction to his } \\
\text { sister's wishes, Fabrice } \\
\text { believes that it would be better } \\
\text { to place their mother in an } \\
\text { institution. }\end{array}$ & $\begin{array}{l}\text { How does this information } \\
\text { influence the hypothesis? }\end{array}$ \\
\hline $\begin{array}{l}\text { Question } 4 \text { - If you are } \\
\text { thinking to } \ldots\end{array}$ & And then ... & \\
\hline $\begin{array}{l}\text {... encourage Marie and } \\
\text { Fabrice to express their } \\
\text { feelings and experiences of } \\
\text { the last few months regarding } \\
\text { their relationship with their } \\
\text { mother. }\end{array}$ & $\begin{array}{l}\text {.. Marie complains about her } \\
\text { mother's verbal and motor } \\
\text { aggressiveness as a result of } \\
\text { the illness. Fabrice, for his } \\
\text { part, feels that he has already } \\
\text { grieved. }\end{array}$ & $\begin{array}{l}\text { How does this information } \\
\text { influence the hypothesis? }\end{array}$ \\
\hline uestion 5 - Taking into acc & all the facts of the situatio & at are your thoughts? What is \\
\hline
\end{tabular}

Figure 2. Questions $(\mathrm{n}=5)$ from the Think-aloud individual interview guide

Three criteria were used to analyze the data collected during the individual interviews: 1-early representation of the simulated situation, 2-semantic transformation, and 3-hypothesis comparison. These three criteria are closely related, that is, an initial representation of the simulated situation ${ }^{[36,37]}$ activated by the scripts allows for the use of semantic qualifiers to demonstrate an understanding thereof. ${ }^{[12,38]}$ In order to resolve the clinical situation, the scripts activate the comparison of hypotheses, in particular by searching for additional data, ${ }^{[17]}$ and continuously and iteratively enrich the CR hypotheses processes. ${ }^{[12,38]}$ Table 1 presents criteria for assessing CR that were translated into indicators to support the analysis of the data. The indicators were deduced by the researcher from the definition of each criterion by Faucher et al. ${ }^{[17]}$ Finally, the questions used in the five SCT vignettes are related to the indicators analyzed for each criterion.
The data collected was organized in the form of a detailed summary of individual cases ${ }^{[29]}$ that included descriptive data related to the three criteria for each student. The indicator data were then analyzed more broadly for synthesis and comparison between first- and third-year students. Speech segments were used to exemplify the conclusions drawn for each of the CR indicators to ensure the transparency and the credibility of the data reported and to facilitate comparison between investigators. ${ }^{[39,40]}$

Analyses were conducted by the primary researcher and a triangulation of data analysis was carried out through confirmation with the second author. Both were familiar with the cognitive task and had previous research experience related to $\mathrm{CR}$ evaluation, to increase the reliability and the consistency of data analysis. ${ }^{[23]}$ Finally, sociodemographic data were analyzed using descriptive statistics. 
Table 1. CR criteria according to script theory, indicators analyzed, and SCT questions

\begin{tabular}{|c|c|c|c|c|}
\hline \multicolumn{5}{|c|}{ Criterion 1: Representing a situation } \\
\hline \multicolumn{3}{|c|}{ Indicators } & \multicolumn{2}{|c|}{ SCT questions } \\
\hline \multicolumn{3}{|c|}{$\begin{array}{l}\text {-Demonstrating a quick understanding of the situation during the CR process } \\
\text {-Summarizing the situation data in one or two sentences }\end{array}$} & \multicolumn{2}{|c|}{$\begin{array}{l}\text { What is happening in this situation? What are your } \\
\text { thoughts at this moment? } \\
\text { Taking into account all of the vignette elements, } \\
\text { what are your thoughts? What is your impression? }\end{array}$} \\
\hline \multicolumn{5}{|c|}{ Criterion 2: Semantic transformation } \\
\hline \multicolumn{4}{|c|}{ Indicators } & SCT questions \\
\hline \multicolumn{4}{|c|}{$\begin{array}{l}\text {-Wording of identified data } \\
\text {-Use of semantic qualifiers to translate data in terms of professional practice. The student’s discourse is } \\
\text { either reduced, dispersed, elaborated, or compiled according to the typology developed by Bordage }{ }^{[18]} \\
\text { adapted by Nendaz et al. }{ }^{[38]}\end{array}$} & \multirow{3}{*}{$\begin{array}{l}\text { What is happening in } \\
\text { this situation? What are } \\
\text { your thoughts at this } \\
\text { moment? } \\
\text { If you are thinking to... } \\
\text { And then..., how does } \\
\text { this new information } \\
\text { influence the } \\
\text { hypothesis? } \\
\text { Taking into account all } \\
\text { of the vignette elements, } \\
\text { what are your thoughts? } \\
\text { What is your } \\
\text { impression? }\end{array}$} \\
\hline Reduced & Dispersed & Elaborated & Compiled & \\
\hline $\begin{array}{l}\text {-Reduced, scattered, or poorly defined } \\
\text { discourse } \\
\text {-Use of little or no semantic qualifier } \\
\text {-Speech that does not reflect } \\
\text { transformation or connection between the } \\
\text { data of the situation and the student's } \\
\text { knowledge }\end{array}$ & $\begin{array}{l}\text {-Long-winded, poorly } \\
\text { defined, or scattered } \\
\text { discourse } \\
\text {-Use of few semantic } \\
\text { qualifiers } \\
\text {-Hypotheses are } \\
\text { formulated but they } \\
\text { are disordered, fail to } \\
\text { refer to the } \\
\text { information about the } \\
\text { situation, and they are } \\
\text { listed without being } \\
\text { compared with one } \\
\text { another }\end{array}$ & $\begin{array}{l}\text {-Long-winded } \\
\text { discourse, } \\
\text { with use of } \\
\text { few semantic } \\
\text { qualifiers to } \\
\text { accurately } \\
\text { describe the } \\
\text { facts of a } \\
\text { situation } \\
\text {-Hypotheses } \\
\text { are formulated } \\
\text { and compared } \\
\text { with one } \\
\text { another }\end{array}$ & $\begin{array}{l}\text {-Discourse is both concise } \\
\text { and semantically rich } \\
\text {-A set of identified and } \\
\text { grouped data is associated } \\
\text { with one or more hypotheses }\end{array}$ & \\
\hline \multicolumn{5}{|c|}{ Criterion 3: Comparing different hypotheses } \\
\hline \multicolumn{3}{|c|}{ Indicators } & \multicolumn{2}{|c|}{ SCT questions } \\
\hline \multicolumn{3}{|c|}{$\begin{array}{l}\text {-Correlating similarities and differences between the data associated with } \\
\text { the different hypotheses } \\
\text {-Ranking hypotheses and explaining why one is chosen over another } \\
\text {-Formulating other hypotheses than those proposed }\end{array}$} & \multicolumn{2}{|c|}{$\begin{array}{l}\text { What is happening in this situation? What are your } \\
\text { thoughts at this moment? } \\
\text { If you are thinking to... And then ..., how does this } \\
\text { new information influence the hypothesis? } \\
\text { Taking into account all of the vignette elements, } \\
\text { what are your thoughts? What is your impression? }\end{array}$} \\
\hline
\end{tabular}

\subsection{Ethical considerations}

The study was approved by the health research ethics board of a Canadian university (\# 17-156-CERES-D). All participants gave their free, informed consent by signing a consent form. Participants were informed that their participation in this study was not linked to any evaluation of their performance in the educational program.

\section{RESULTS}

\subsection{Sociodemographic data}

A total of 18 students, nine first-year and nine third-year students participated in the study. Participants were mainly women $(n=15,83 \%)$, aged between 26 and $35(n=13,72 \%)$. Most students had done no prior studies in the health and social services field $(n=12,66 \%)$. Slightly more than half of them had worked in the health and social services field (n $=10,56 \%)($ see Table 2$)$.

Table 3 summarizes the results that emerged from the study of the three criteria of students' CR based on script theory, for the combined use of think-aloud and SCT questions.

\subsection{Observations of CR criteria according to script the- ory}

The results show that the three criteria of script use are present in the students' quotes: early representation of a situation, semantic transformation of data, and hypothesis comparison. Therefore, the phenomenon of interest (activation and confrontation of hypotheses with SCT questions and TA) triggered the $\mathrm{CR}$ cognitive operations. Because of the missing situation data, the SCT questions forced students 
to make frequent micro-judgments, which required a preliminary representation of the situation. The TA exercise involved semantic transformation of the data described in the SCT questions in order to judge and compare hypotheses. In short, SCT questions combined with TA triggered a process of CR in students.

Experiences from clinical internships helped students to better articulate their thought processes, which theoretically refers to the densification of scripts with years and clinical experience. Presenting a slightly more elaborate discourse, third-year students seemed to do more semantic transformation of data. Conversely, there was no marked difference between students for the other two criteria. All students took reflective pauses throughout the exercise to process the data and solidify some of the relationships between data.
Table 2. Sociodemographic data of participating students ( $=18$ )

\begin{tabular}{lll}
\hline Items & & $\mathbf{N}=\mathbf{1 8}$ \\
\hline \multirow{2}{*}{ Sex } & Male & $3(17)$ \\
& Female & $15(83)$ \\
& Under 20 years of age & $3(17)$ \\
& 21 to 25 & 0 \\
Age & 26 to 30 & $13(72)$ \\
& 31 to 40 & $2(11)$ \\
Prior studies in the health and & Yes years of age and over & 0 \\
social services field & No & $6(33)$ \\
Work experience in the health & Yes & $12(66)$ \\
and social services field & No & $10(56)$ \\
\hline
\end{tabular}

Table 3. Observations of CR criteria in students, according to script theory, when using think-aloud method and SCT questions

\begin{tabular}{|c|c|c|c|c|}
\hline Criteria & \multicolumn{2}{|l|}{ Absence of script } & \multicolumn{2}{|l|}{ Nascent scripts } \\
\hline $\begin{array}{l}\text { Representing } \\
\text { the situation }\end{array}$ & \multicolumn{2}{|c|}{$\begin{array}{l}\text {-Statement copied from what was already presented } \\
\text { in writing } \\
\text {-Use of data from the situation only } \\
\text {-No links established between the data used }\end{array}$} & \multicolumn{2}{|c|}{$\begin{array}{l}\text {-Identification of the data that is determining in the } \\
\text { situation } \\
\text {-Generalization or discrimination between identified data } \\
\text { which are then linked to the student's experience } \\
\text {-Stating additional information to be sought that could be } \\
\text { related to the situation in order to formulate a nursing } \\
\text { hypothesis or to judge the plausibility thereof }\end{array}$} \\
\hline & Reduced discourse & Dispersed discourse & Elaborated discourse & Compiled discourse \\
\hline $\begin{array}{l}\text { Semantic } \\
\text { transformation }\end{array}$ & $\begin{array}{l}\text {-No verbal statement } \\
\text {-Brief and limited } \\
\text { discourse or long-winded } \\
\text { discourse with no common } \\
\text { thread } \\
\text {-No use or limited use of } \\
\text { semantic qualifiers }\end{array}$ & $\begin{array}{l}\text {-Stating some } \\
\text { semantic qualifiers or } \\
\text { characteristics of the } \\
\text { situation data } \\
\text {-Discourse that is } \\
\text { scattered or poorly } \\
\text { representative of the } \\
\text { context of the } \\
\text { simulated situation }\end{array}$ & $\begin{array}{l}\text {-Relationships between } \\
\text { data are made explicit } \\
\text {-Use of semantic } \\
\text { qualifiers to translate } \\
\text { data in terms of } \\
\text { professional practice }\end{array}$ & $\begin{array}{l}\text {-Relationship between data } \\
\text { and the strength of } \\
\text { associations is made explicit } \\
\text {-Use of professional semantic } \\
\text { qualifiers } \\
\text {-Concise verbalisation } \\
\text { reflecting a contextualised } \\
\text { description of the care } \\
\text { situation }\end{array}$ \\
\hline $\begin{array}{l}\text { Hypothesis } \\
\text { comparison }\end{array}$ & \multicolumn{2}{|c|}{$\begin{array}{l}\text {-Lack of focus to guide the gathering of data in order } \\
\text { to confirm/refute a hypothesis } \\
\text {-No comparison between hypotheses } \\
\text {-Statement of standardized hypotheses, which are } \\
\text { not, however, related to situational data }\end{array}$} & \multicolumn{2}{|c|}{$\begin{array}{l}\text {-Focused data gathering to confirm/refute a nursing } \\
\text { hypothesis } \\
\text {-Correlating similarities and differences between the data } \\
\text { associated with the different hypotheses } \\
\text {-Explaining the prioritization of one nursing hypothesis } \\
\text { over another } \\
\text {-Statement of possible hypotheses in addition to those } \\
\text { proposed }\end{array}$} \\
\hline
\end{tabular}

\subsubsection{Early representation of a situation}

For the situation representation, students at both levels of training felt the need to read the clinical situation aloud several times after the researcher had read it aloud once. Only after rereading twice or three times, they would give their initial impression. Rereading the situation seemed to help the

Published by Sciedu Press students to understand the simulated situation. At this point, the triggered cognitive CR strategy involved identification or singling out of the situation's key elements, illustrated by the student's discourse.

When answering the first question of the interview (What 
is happening in this situation? What are your thoughts at this moment?), students frequently used a brief explanatory discourse to make some connections between the clinical situation data, to propose hypotheses, or to identify some additional information required for the formulation of a hypothesis, as shown in the following two passages linked to the vignette shown in Figure 2.

Fabrice says he has already grieved. Why is it like this and what brought him to this? How does Marie experience her mother's aggressiveness? Both children have opposite feelings. We should talk with them. Why do they have these feelings?

We need to explore what's going on in the family right now. Why is she feeling exhausted? Is it because she has health issues or because her mother's condition is too hard to cope with? The important thing to do here is to explore the situation and the concerns of the family and the lady in question.

The failure of some students to interweave the situational data and their knowledge seemed to limit their ability to formulate a hypothesis. In addition, some linkages between the data were created that mirrored what students had already learned in clinical placements or in other educational strategies such as problem-based learning. The two comments below illustrate this.

I'm disappointed right now. My knowledge of wound care is too limited to allow me to identify the appropriate care required, i.e., the choice of wound dressing. I don't know how to respond.

I encountered a similar situation during my internship. This type of behaviour often indicates that the patient may not be sufficiently informed about her situation.

\subsubsection{Semantic transformation of situation data}

The analysis based on semantic transformation encompassed all the data that emerged during the exercise. Observed more frequently in third-year students, an elaborate and even compiled discourse (see indicators observed in Table 3) demonstrated the establishing of relationships between the situation data and the student's ability to single out the determining data. At that point, students were able to generalize or discriminate the data when relating it to similar situations encountered during clinical practicum, for example. Students were able to interpret the data in the context of processing them. They used qualifiers illustrating the meaning attributed to the situation data. At other times, students stated additional information that needed to be collected in order to strengthen their $\mathrm{CR}$, as shown in the following two passages:

I'm thinking of the feeling of heaviness that the loved one is experiencing. I wonder about this person's resources. I would check the task sharing between the two children and their degree of involvement. I would get the person to talk about her fatigue and where she's in overcoming the situation, i.e., in accepting her mother's condition.

I'm thinking delirium. She's both agitated and confused. There's something going on. But there are several explanations possible. Unfamiliar surroundings also predispose her to this.

In contrast, first-year students and some third-year students presented a reduced or dispersed discourse (see indicators observed in Table 3). This type of discourse was illustrated by comments in which students repeated what was already presented in the simulated situation. The information was analyzed without establishing relationships between data. Students stated certain types of standardized care (e.g., protocol) that was not contextualized to the situation. In addition, the inability to establish connections between knowledge or experience in some situations left students "speechless". Discourse remained superficial and lacking in identification of new information to be researched and analyzed, or it was scattered, poor in interpretive nuance (e.g., patient is well/not well), and unrepresentative of the context of the situation, showing an absence of correlation between data. The two segments below illustrate limited and scattered discourse.

The patient is not doing well. It's not going well. All the information in the nursing treatment plan is not necessarily interrelated. Maybe it is? [...] The patient has multiple diseases.

The patient's in bad shape. There have been complications [...]. That's it, he's not doing well.

\subsubsection{Comparison between different hypotheses}

Overall, the students' discourse reveals that their hypothesis development remained cursory. Students stated one or two hypotheses after the first question following the clinical situation (What is happening in this situation? What are your thoughts at this moment?). When analyzing the interviews, the researcher also noted prioritization or ranking of hypotheses and the formulation of other hypotheses in addition to those described in the SCT questions, as shown in the following passage:

ISSN 1925-4040 E-ISSN 1925-4059 
The new information makes me think of a possible delirium than a risk of immobilization [...]. But it's still a relevant hypothesis. The altered state of consciousness questions me and makes me believe of a delirium.

The students' discourse reveals a search for additional information to guide data collection, and to enrich and support scripts with a view to developing nursing clinical hypotheses. Some comparison of key elements in order to regroup or distinguish hypotheses was perceived, especially in third-year students. These students prioritized one hypothesis out of those proposed to them. The question, "If you thought ... and then ... how does this new information influence the hypothesis?", which was asked more than once during the interview, seemed to help students to discriminate between the situational data, which they related to their knowledge.

The final question for each of the five SCT situations "Taking into account all the data provided in the vignette, what are your thoughts? What is your impression?" lead some students to new assumptions aside from those previously suggested. Most of them reread or repeated all the elements of the vignette in order to take stock and interpret the overall situation. The students' discourse suggests a cumulative understanding of the data rather than a ranking of hypotheses. Two students expressed this interpretive synthesis of a situation:

His condition is deteriorating... I'd keep a close watch. Have there been any changes in his vital signs? He's confused... Could he be at risk of delirium?

Here, I'd order a blood count and a white blood cell count to confirm. Delirium can be triggered by an infection, and elderly persons don't always develop a fever. There are many factors in the situation that can predispose to an episode of delirium.

\section{Discussion}

Eighteen students were interviewed. At the time of collection and analysis ${ }^{[41]}$ this sample size was deemed to be appropriate for achieving data saturation, which was found to be the case. The study highlighted two findings: 1-the educational strategy linking SCT question and the TA method promote CR-related cognitive operations and 2-nursing undergraduate students lack practice regarding this type of educational strategy.

The findings show that the educational strategy linking SCT questions and the TA method would promote CR-related cognitive operations such as the articulation of knowledge and the linking of knowledge to data in a clinical situation, as well as the use of micro-judgments to compare hypotheses. This educational intervention might enhance student scripts and trigger hypothesis development. The results are in line with those reported by Banning ${ }^{[22]}$ and Burbach et al. ${ }^{[22]}$ who concluded that TA makes the articulation of knowledge observable and that it is an educational intervention that promotes CR in nursing. In our study, it also promoted the frequent use of student micro-judgments to compare and differentiate hypotheses that are representative of the uncertainty in clinical practice. The articulation of knowledge and the development of links between knowledge and clinical situation data promote in-depth learning ${ }^{[43,44]}$ and, consequently, the students' cognitive processes of CR. ${ }^{[22]}$ These cognitive processes, which are frequently called upon, underpin skills learning in successive layers. ${ }^{[43,44]}$

The findings illustrate the fact that the students' wording, reflecting CR cognitive operations, exhibited knowledge of the discipline. Bordage's typology of discourse addresses the semantic transformation of illness scripts in the medical sciences. In our study, the discourse typology was refined in light of nursing knowledge, that is, a care experience that includes the interrelation between the health problem, the individual/family, the nurse, and the environment in a systemic perspective of CR in nursing. ${ }^{[9,45]}$ This perspective makes it possible to use the term "experience-scripts" to refer to knowledge organization. This is consistent with the systemic view of $\mathrm{CR}$ adopted by a number of authors in the nursing literature..$^{[9,20,21,46]}$

The findings show that students' lack of practice in CR cognitive operations limits CR learning and development. In this study, students frequently paused to think or lacked words, which may be showing lack of knowledge and clinical experience or their difficulty in demonstrating their knowledge. These findings are similar to those reported in other nursing studies. ${ }^{[9,47]}$ Of course, there will be no hypothesis development if there is a lack of knowledge or clinical experience. But the findings also demonstrate that students do not sufficiently practice linking their knowledge to clinical situation data in order to make their knowledge usable in simulated context. This is an obstacle to the development of nursing clinical hypotheses requiring ongoing supervision, education and support. This finding is consistent with Hunter et al. ${ }^{[48]}$ research. These authors conducted semi-structured interviews with clinical instructors $(n=10)$ in order to understand how they perceived CR in nursing students and the strategies they used to support its development and evaluation in a clinical setting. All clinical instructors identified their questioning as an educational strategy used to support 
student CR. However, they referred to questions that asked students to justify their interventions without eliciting different elements of their CR processes. They suggest that students practice $\mathrm{CR}$ through the use of questioning for all the processes involved in $\mathrm{CR}$, from recognizing cues and collecting data to reinforce or minimize a hypothesis and finally, to iterative evaluation of interventions through reflecting on action. ${ }^{[48]}$ As observed in our study, by prompting the student to reason aloud, the instructor can uncover and evaluate the $\mathrm{CR}$ processes used by the student.

The findings illustrating the students' "lack of words" may also be explained by the absence of reflective role models or discussions with peers or an instructor to guide the exercise, as evidenced by our previous study where we used an educational strategy in which nursing experts had made answer choices and provided comments to explain their choices. ${ }^{[15,16]}$ Tedesco-Schneck ${ }^{[8]}$ also experimented an educational practice combining SCT questions and TA in a pediatric nursing course. Following the completion of the SCT questions, a classroom workshop was facilitated to stimulate the students' TA and initiate discussion. The author emphasizes the contribution of TA in facilitating the understanding of decision-making processes and in clarifying erroneous CR in nursing. Peer discussion and the sharing of different perspectives were reported to help students to better grasp the complexity of CR. ${ }^{[8]}$ Burbach et al. ${ }^{[42]}$ integrated a TA method in a high-fidelity clinical simulation setting with undergraduate nursing students. The authors concluded that this educational strategy supports CR learning. In addition, they reported that it provided insight into the way students selected data deemed meaningful in the simulation. Students were also asked to narrate their choices of explanation and nursing intervention hypotheses and to reflect on action, both of which are essential to CR.

In summary, the findings of this study provide valuable information for educators. Having test-takers verbalize their rationale while responding to SCT questions provide a broader assessment of CR that is otherwise lost in the current format of SCT questions. In addition, it seems that current educational strategies make little use of TA method to promote students' activation and confrontation of hypotheses in contexts of uncertainty, even though these contexts are ubiquitous in clinical practice. They suggest the introduction of TA exercises, including SCT questions, as a method to support $\mathrm{CR}$ learning in clinical settings. Cognitive dialogue based on clinical practice situations, which are linked to SCT questions and referencing tools, is of particular interest because knowledge and concrete examples become interdependent and promote learning. ${ }^{[49]}$ Used repeatedly during students' training, this type of questioning and TA could expand the repertoire of knowledge and its organization (scripts) and thus facilitate CR development.

Finally, this study helped to strengthen our understanding of the contribution of SCT questions to promoting microjudgments and students script development. This is an original study that allows us to better grasp the contribution of the digital educative strategy based on script concordance components. In this study, TA was only used at one stage of the strategy, namely the SCT questions. It could also be added to the other stages, following the viewing of expert feedback and referencing tools. In addition, it would also be of interest to find out at what point during the TA exercise students are able to effectively organize their thinking in support of their CR process.

\section{Study limitations}

In this study, CR learning from vignette presentation was based on simulated nursing practice situations. We cannot ascertain that the cognitive effort generated in the context of this educational strategy is comparable to actual contact in a clinical practice setting. This situation marks a certain limitation of the study by emphasizing the fact that explanations based on a written vignette do not immediately mobilize scripts as would a clinical action situation. TA method and using SCT vignettes also require a lot of resources to effectively support CR learning. Transcription, listening to, and analysis of students' thinking aloud is time consuming and hence of limited use with large groups of students during their academic program. Its use would therefore be much more appropriate in a clinical practice context during preceptorship or mentorship, for example. In light of current digital innovation, integrating the recording of TA within the digital environment can also be considered, thus allowing reducing the resources required for data transcription.

\section{Conclusion}

Albeit essential to CR, strategies for generating student nursing clinical hypotheses at the time of transition to professional practice are underdeveloped. ${ }^{[9,47]}$ Introducing nursing hypothesis development earlier in the education program is therefore warranted with a view to enhancing student knowledge, through planned metacognitive exercises. The combined use of TA method based on SCT questions is a promising strategy for promoting CR learning. Used a few times during the academic training and clinical practicum, SCT questions could expand students' knowledge and nascent scripts, thereby facilitating the development of nursing hypotheses. Supported by digital innovation, future research could integrate elements such as TA exercises with other components of the digital educational strategy based on scripts 
concordance in order to promote optimal CR learning and development.

\section{ACKNOWLEDGEMENTS}

The first author received doctoral scholarships from the Social Sciences and Humanities Research Council of Canada (SSHRC), the Université de Montréal's CIFI (Centre d'innovation en formation infirmière), the FUTUR team, a re- search infrastructure subsidized by the FRQSC, the Ministère de l'Éducation et de l'Enseignement supérieur (MEES) in Quebec; the Fonds de recherche du Québec - Société et culture (FRQ-SC); and the Faculty of Nursing of the Université de Montréal.

\section{Conflicts of InTEREST Disclosure}

The authors have no conflict of interest to declare.

\section{REFERENCES}

[1] Jessee MA. Pursuing improvement in clinical reasoning: the integrated clinical education theory. Journal of Nursing Education. 2018; 57(1): 7-13. PMid:29381154 https://doi.org/10.3928/0148 4834-20180102-03

[2] Brown Tyo M, McCurry MK. An integrative review of clinical reasoning teaching strategies and outcome evaluation in nursing education. Nursing Education Perspectives. 2019; 40(1): 11-17. PMid:30095730 https://doi.org/10.1097/01.NEP.0000000000000375

[3] Daniel M, Rencic J, Durning SJ, et al. Clinical reasoning assessment methods: a scoping review and practical guidance. Academic Medecine. 2019; 94(6): 902-912. PMid:30720527 https: //doi.org/10.1097/ACM.0000000000002618

[4] Dawson TE, Comer L, Kossick MA, et al. Can script concordance testing used in nursing education to accurately assess clinical reasoning skills? Journal of Nursing Education. 2014; 53(5): 281-286. PMid:24641082 https : //doi .org/10.3928/01484834-20140 321-03

[5] Deschênes MF, Charlin B, Gagnon R, et al. Use of a Script Concordance Test to Assess Development of Clinical Reasoning in Nursing Students. Journal of Nursing Education. 2011; 50(7): 381-387. PMid:21449528 https : //doi .org/10.3928/01484834-20110 331-03

[6] Gawad N, Wood TJ, Cowley L, et al. The cognitive process of test takers when using the script concordance test rating scale. Medical Education. 2020; 54(4): 337-347. PMid:31912562 https: //doi.org/10.1111/medu.14056

[7] Power A, Lemay JF, Cooke S. Justify your Answer: The Role of Written Think Aloud in Script Concordance Testing. Teaching and Learning in Medicine. 2016; 29(1): 1-9. PMid:27662118 https ://doi.org/10.1080/10401334.2016.1217778

[8] Tedesco-Schneck M. Use of Script Concordance Activity With the Think-Aloud Approach to Foster Clinical Reasoning in Nursing Students. Nurse educator. 2019; 44(5): 275-277. PMid:30394999 https://doi.org/10.1097/NNE.0000000000000626

[9] Goudreau J, Boyer L, Létourneau D. Clinical Nursing Reasoning in Nursing Practice: A Cognitive Learning Model based on a Think Aloud Methodology. Quality Advancement in Nursing Education - Avancées en formation infirmière. 2014; 1(1): 1-18. https://doi.org/10.17483/2368-6669.1009

[10] Abelson RP. Concepts for representing mundane reality in plans. In: Bobrow DG, Collins A, editors. Representation and understanding: Studies in cognitive science. New-York: Academic Press; 1975. p. 273-309.

[11] Schank R, Abelson R. Script, Plans, Goals and Understanding: An Inquiry into Human Knowledge Structures. Hillsdale, New Jersey: Lawrence Erlbaum Associates; 1977.
[12] Charlin B, Tardif J, Boshuizen HPA. Scripts and medical diagnostic knowledge: Theory and applications for clinical reasoning instruction and research. Academic Medecine. 2000; 75(2): 182-190. PMid:10693854 https ://doi .org/10.1097/00001888-20000 2000-00020

[13] Lubarsky S, Dory V, Audétat MC, et al. Using script theory to cultivate illness script formation and clinical reasoning in health professions education. Canadian Medical Education Journal. [Internet] 2015 [cited 2015 Dec 11]; 6(2): e61-e70. https ://doi.org/10.3 $6834 / \mathrm{cmej} .36631$

[14] Deschênes MF, Goudreau J. Addressing the development of both knowledge and clinical reasoning in nursing through the perspective of script concordance: an integrative literature review. Journal of Nursing Education and Practice. 2017; 7(12): 28-38. https : //doi.org/10.5430/jnep.v7n12p28

[15] Deschênes MF, Goudreau J, Fernandez N. Learning strategies used by undergraduate nursing students in the context of a digital educational strategy based on script concordance: A descriptive study. Nurse Education Today. 2020; 95: 1-9. PMid:33045676 https : //doi.org/10.1016/j.nedt.2020.104607

[16] Deschênes MF, Goudreau J. L'apprentissage du raisonnement clinique infirmier dans le cadre d'un dispositif éducatif numérique basé sur la concordance de scripts. Pédagogie médicale. 2020; 21: 143 157. https://doi.org/10.1051/pmed/2020041

[17] Faucher C, Pelaccia T, Nandaz M, et al. Un professionnel de la santé qui résout efficacement les problèmes : le raisonnement clinique. In: Pelaccia T, editor. Comment (mieux) former et évaluer les étudiants en médecine et en sciences de la santé? Bruxelles, Belgique: De Boeck; 2016. p. 33-44.

[18] Bordage G. Elaborated knowledge: a key to successful diagnostic thinking. Academic Medicine. 1994; 69(11): 883 885. PMid:7945684 https://doi.org/10.1097/00001888-1 99411000-00004

[19] Bordage G. La prise de décision en médecine: quelques mécanismes mentaux et des conseils pratiques. La revue de médecine interne. 2005; 26: S14-S17. PMid:15922847 https://doi.org/10.101 6/j.revmed. 2005.04 .012

[20] Tanner CA. Thinking like a nurse: A research-based model of clinical judgment in nursing. Journal of Nursing Education. 2006; 45(6): $204-$ 211. PMid:16780008 https://doi.org/10.3928/01484834-2 0060601-04

[21] Simmons B. Clinical reasoning: concept analysis. Journal of Advanced Nursing. 2010; 66(5): 1151-1158. PMid:20337790 https : //doi.org/10.1111/j.1365-2648.2010.05262.x

[22] Banning M. The think aloud approach as an educational tool to develop and assess clinical reasoning in undergraduate students. Nurse Education Today. 2008; 28(1): 8-14. PMid:17383056 https : //doi.org/10.1016/j.nedt.2007.02.001 
[23] Fonteyn ME, Kuipers B, Grobe SJ. A description of think aloud method and protocol analysis. Qualitative Health Research. 1993; 3: 430-441. https : //doi.org/10.1177/104973239300300403

[24] Newell A, Simon HA. Human problem solving. Englewood Cliffs, NJ: Prentice-Hall 1972.

[25] Van Someren M, Barnard Y, Sandberg J. Studying the content of cognitive processes. In: Van Someren M, Barnard Y, Sandberg J, editors. The Think Aloud Method: A practical guide to modelling cognitive processes. London, UK: Academic Press; 1994. p. 13-26.

[26] Yin RK. Case study research and applications: Design and methods. 3 ed. Thousand Oaks: Sage publications; 2003.

[27] Creswell JW. Research design, qualitative, quantitative and mixed methods approaches. 4 ed. Los Angeles: Sage Publications; 2014 English.

[28] Creswell JW. Qualitative inquiry \& research design : choosing among five approaches. 3 ed. Thousand Oaks: Sage Publications; 2013. English.

[29] Miles MB, Huberman AM. Analyse des données qualitatives. 2 ed. Bruxelles: De Boeck Supérieur; 2003.

[30] Heale R, Twycross A. What is a case study? Evidence Based Nursing. 2018; 21(1): 7-8. PMid:29146764 https://doi.org/10.1136/ eb-2017-102845

[31] Yin RK. Case study research and applications: Design and methods. 6 ed. Thousand Oaks, CA: Sage publications; 2017.

[32] Ericsson KA, Simon HA. Verbal reports as data. Psychological Review. 1980; 87: 215-251. https ://doi .org/10.1037/0033-295 $\mathrm{x} .87 .3 .215$

[33] Dumont K, Loye N, Goudreau J. Le potentiel diagnostique des questions d'un test de concordance de scripts pour évaluer le raisonnement clinique infirmier. Pédagogie Médicale. 2015; 16(1): 49-64. https://doi.org/10.1051/pmed/2015012

[34] Boyer L, Pepin J, Dubois S, et al. Adaptation and validation of a nursing competencies framework for clinical practice on a continuum of care from childhood to adulthood: A Delphi study. Nurse Education Today. 2020; 93: 104530. PMid:32653535 https : //doi.org/10.1016/j.nedt.2020.104530

[35] Charlin B, Boshuizen HPA, Custers EJ, et al. Scripts and clinical reasoning. Medical Education. 2007; 41: 1178-1184. PMid:18045370 https://doi.org/10.1111/j.1365-2923.2007.02924.x

[36] Chang RW, Bordage G, Connell KJ. Cognition, Confidence, and Clinical Skills: The Importance of Early Problem Representation During Case Presentations. Academic Medicine. 1998; 73(10): S109-111. PMid:9795669 https://doi.org/10.1097/000018 88-199810000-00062

[37] Eva KW. What every teacher needs to know about clinical reasoning. Medical education. 2005; 39(1): 98-106. PMid:15612906 https ://doi.org/10.1111/j.1365-2929.2004.01972.x
[38] Nendaz M, Charlin B, Leblanc V, et al. Le raisonnement clinique: données issues de la recherche et implications pour l'enseignement. Pédagogie Médicale. 2005; 6(4): 235-254. https://doi .org/10 .1051/pmed : 2005028

[39] Bradshaw C, Atkinson S, Doody O. Employing a qualitative description approach in health care research. Global Qualitative Nursing Research. 2017; 4: 1-8. PMid:29204457 https ://doi .org/10.1 $177 / 2333393617742282$

[40] Graneheim UH, Lindgren BM, Lundman BJN. Methodological challenges in qualitative content analysis: A discussion paper. 2017; 56: 29-34. PMid:27429396 https ://doi.org/https://doi .or g/10.1016/j.nedt.2016.06.002

[41] Morse JM. Determining sample size. Qualitative health research. 2000; 10(1): 3-5. https ://doi.org/10.1177/10497320012911 8183

[42] Burbach B, Barnason S, Thompson S. Using "Think Aloud" to Capture Clinical Reasoning during Patient Simulation. International Journal of Nursing Education Scholarship. 2015; 12(1): 1-7. PMid:25719341 https://doi.org/10.1515/ijnes-2014-004 4

[43] Jouquan J, Romanus C, Vierset V, et al. Promouvoir les pédagogies actives comme soutien à la pratique réflexive et à l'apprentissage en profondeur. In: Parent F, Jouquan J, editors. Penser la formation des professionnels de la santé: une perspective intégrative. Bruxelles: De Boeck supérieur; 2013. p. 245-283.

[44] Tardif J. Ancrer les apprentissages sur les connaissances antérieures des étudiants. In: Pelaccia T, editor. Comment (mieux) former et évaluer les étudiants en médecine et en sciences de la santé? . Bruxelles, Belgique: De Boeck Supérieur; 2016. p. 149-167.

[45] Pepin J, Ducharme F, Kérouac S. La pensée infirmière. 4 ed. Montréal: Chenelière Éducation; 2017.

[46] Levett-Jones T, Hoffman K, Dempsey J, et al. The 'five rights' of clinical reasoning: an educational model to enhance nursing strudent's ability to identify and manage clinical 'at risk' patients. Nurse Education Today. 2010; 30(6): 515-520. PMid:19948370 https://doi.org/10.1016/j.nedt.2009.10.020

[47] Boyer L, Tardif J, Lefebvre H. From a Medical Problem to a Health Experience: How Nursing Students Think in Clinical Situations. Journal of Nursing Education. 2015; 54(11): 625-632. PMid:26517074 https : //doi.org/10.3928/01484834-20151016-03

[48] Hunter S, Arthur C. Clinical reasoning of nursing students on clinical placement: Clinical educators' perceptions. Nurse Education in Practice. 2016; 18: 73-79. PMid:27235568 https://doi.org/10 $.1016 / j$. nepr. 2016.03.002

[49] Renkl A. Toward an instructionally oriented theory of example-based learning. Cognitive science. 2014; 38(1): 1-37. PMid:24070563 https ://doi.org/10.1111/cogs. 12086 